\title{
Spectra of Homologous Series of Monosubstituted Amides
}

\author{
M. Beer, ${ }^{*}$ H. B. Kessler, $†$ AND G. B. B. M. SUtherLand $\ddagger$ \\ H. M. Randall Laboratory of Physics, University of Michigan, Ann Arbor, Michigan
}

(Received June 26, 1958)

\begin{abstract}
Infrared spectra of the pure liquid and of dilute solution were observed for $\mathrm{N}$-methyl, $\mathrm{N}$-ethyl, N-propyl, and $\mathrm{N}$-butyl acetamides and propionamides and of $\mathrm{N}$-deuterated $\mathrm{N}$-butylacetamide. Also infrared spectra of $\mathrm{N}^{15}$-butylacetamide and $\mathrm{N}$-deuterated $\mathrm{N}^{15}$-butylacetamide and the Raman spectra of $\mathrm{N}$-butylacetamide and $\mathrm{N}$-deuterated $\mathrm{N}$-butylacetamide were observed. In each series a band in the higher members was related to each band of the N-methyl compound on the basis of similarity in frequency, intensity, band width, and the influence of dilution. In N-methylacetamide and N-butylacetamide bands thus related were found to have also similar Raman activities and similar shifts on replacing the peptide hydrogen by deuterium. The extra bands could be related systematically to the extra $\mathrm{CH}_{2}$ groups. The implications of these results in protein spectroscopy and in the spectroscopic study of homologous series is discussed.
\end{abstract}

\section{INTRODUCTION}

$\mathbf{T}$ WE infrared spectrum of the amide group has received considerable attention in recent years, largely because in spectroscopic investigations of proteins the amide group plays a key role. Recently Miyazawa $e t$ al. ${ }^{1}$ have reported investigations on simple amides and have arrived at assignments of bands characteristic of the peptide group. DeGraaf and Sutherland ${ }^{2}$ in a very complete study of $\mathrm{N}$-methylformamide and $\mathrm{N}$-deuterated $\mathrm{N}$-methylformamide have proposed assignments for all the bands of these two compounds. Thus a great deal of information exists on vibrations of an isolated peptide link. However, the peptide link in proteins and polypeptides occurs in long polymers with a wide variety of side chains and the sensitivity of bands of the peptide link to adjacent groups of atoms is a continually recurring problem. In an attempt to throw some light on this question infrared studies of two homologous series of peptide-containing substances were undertaken as well as some very detailed studies of individual members of the series. In particular the substitution of deuterium for hydrogen and of $\mathrm{N}^{15}$ for $\mathrm{N}^{14}$ in the peptide link makes it possible to test various assignments which have been the subject of a good deal of controversy.

\section{EXPERIMENTAL}

$\mathrm{N}$-methylacetamide and $\mathrm{N}$-ethylacetamide were obtained from the Eastman Kodak Company, Rochester, N. Y., and were used without further purification. $\mathrm{N}$-propylacetamide, N-butylacetamide, N-methylpropionamide, N-ethylpropionamide, $\mathrm{N}$-propylpropionamide, and $\mathrm{N}$-butylpropionamide were prepared by

* Present address: Department of Biophysics, The Johns Hopkins University, Baltimore, Maryland.

$\dagger$ Present address: E. I. DuPont de Nemours Company, Wilmington, Delaware.

$\ddagger$ Present address: National Physical Laboratory, Teddington, England.

1 Miyazawa, Shimanouchi, and Mizushima, J. Chem. Phys. 24, 408 (1956).

2 D. E. DeGraaf and G. B. B. M. Sutherland, J. Chem. Phys. 26, 716 (1957).
Dr. W. R. Vaughan and his collaborators at the Department of Chemistry, University of Michigan. These workers used the reaction of the acid anhydride with the aqueous amine. The amide was salted out, dried, and distilled. The fractions used had a refractive index within $0.0004^{\circ}$ and a boiling point within $1^{\circ} \mathrm{C}$ of the values given in Table $I$.

Replacement of the peptide $\mathrm{H}$ by $\mathrm{D}$ was accomplished by adding a threefold excess of $\mathrm{D}_{2} \mathrm{O}$ in a dry nitrogen atmosphere, pumping off the heavy water, and repeating this procedure 3 times. Deuterated materials were sealed in $\mathrm{AgCl}$ cells for observation.

The $\mathrm{N}^{15}$-butylacetamide was prepared by Vaughan et al. ${ }^{3}$

The infrared spectra in the $\mathrm{NaCl}$ region were taken on a Model 21 Perkin Elmer double-beam spectrometer. Spectra at longer wavelengths were studied on a Perkin Elmer Model 12C single beam spectrometer with a KRS5 prism and a LiF reststrahlen plate. The Raman spectra were taken on the equipment used by Vidale and Taylor, ${ }^{4}$ except that in the present work all the spectra were taken at room temperature.

The effect of dilution was studied with reagent grade $\mathrm{CCl}_{4}$ and $\mathrm{CS}_{2}$ as solvents in rock salt cells with lead spacers. The cells were approximately $0.1 \mathrm{~mm}$ and 1 $\mathrm{mm}$ long. For compensation of solvent absorption the cell designed by Stuart ${ }^{5}$ was used. These solvents were chosen because everywhere in the rock salt region at least one of them is sufficiently transparent for the study of the spectra of solutions and therefore by using the two in conjunction the dilution effect of every band can be obtained.

\section{OBSERVATIONS}

Infrared spectra were observed for the pure liquid and for dilute solutions of $\mathrm{N}$-methylacetamide, $\mathrm{N}$ ethylacetamide, N-propylacetamide, N-butylacetamide, $\mathrm{N}$-methylpropionamide, $\mathrm{N}$-ethylpropionamide, $\mathrm{N}$ -

\footnotetext{
${ }^{3}$ Vaughan, Andersen, Blanchard, McCane, and Meyer, J. Org. Chem. 20, 819 (1955).

${ }^{4}$ G. Vidale and R. C. Taylor, J. Am. Chem. Soc. 78, 294 (1956).

${ }^{5}$ A. V. Stuart, J. Opt. Soc. Am. 43, 212 (1953).
} 
TABLE I. Physical constants of amides.

\begin{tabular}{|c|c|}
\hline Compound & Physical constants \\
\hline N-methylacetamide & $\begin{array}{l}n_{\mathrm{D}}=1.42930 / 29.8^{\circ} \mathrm{C} \\
\mathrm{mp}=29^{\circ} \mathrm{C} \\
\mathrm{bp}=200-202^{\circ} \mathrm{C} / 750 \mathrm{~mm}\end{array}$ \\
\hline N-ethylacetamide & $\mathrm{bp}=107-108^{\circ} \mathrm{C} / 20 \mathrm{~mm}$ \\
\hline $\mathrm{N}$-propylacetamide & $\begin{array}{l}n_{\mathrm{D}}=1.4344 / 25.1^{\circ} \mathrm{C} \\
\mathrm{bp}=101-103^{\circ} \mathrm{C} / 9 \mathrm{~mm}\end{array}$ \\
\hline N-butylacetamide & $\begin{array}{l}n_{\mathrm{D}}=1.4380 \\
\mathrm{bp}=112-115^{\circ} \mathrm{C} / 8 \mathrm{~mm}\end{array}$ \\
\hline $\mathrm{N}$-methylpropionamide & $\begin{array}{l}n_{\mathrm{D}}=1.4313 / 24.1^{\circ} \mathrm{C} \\
\mathrm{bp}=104^{\circ} \mathrm{C} / 16 \mathrm{~mm}\end{array}$ \\
\hline N-ethylpropionamide & $\mathrm{bp}=94-95^{\circ} \mathrm{C} / 9 \mathrm{~mm}$ \\
\hline N-propylpropionamide & $\begin{array}{l}n_{\mathrm{D}}=1.4397 / 23.7^{\circ} \mathrm{C} \\
\mathrm{bp}=108-109^{\circ} \mathrm{C} / 9 \mathrm{~mm}\end{array}$ \\
\hline N-butylpropionamide & $\begin{array}{l}n_{\mathrm{D}}=1.4397 / 23.7^{\circ} \mathrm{C} \\
\mathrm{bp}=123-126^{\circ} \mathrm{C} / 10 \mathrm{~mm}\end{array}$ \\
\hline
\end{tabular}

propylpropionamide, and $\mathrm{N}$-butylpropionamide. The first four of these substances constitute a homologous series as do also the last four. The spectra of these two homologous series are given in Figs. 1 and 2. Similar observations on $\mathrm{N}$-methylacetamide have already been reported by Miyazawa and co-workers. ${ }^{1}$ The effect of dilution is indicated by small arrows above the bands. Vertical arrows indicate loss or gain of intensity on dilution. Horizontal arrows indicate a shift in the peak position of the band and the numbers in brackets give the magnitude of the shift in $\mathrm{cm}^{-1}$. Figure 3 shows the infrared spectrum of $\mathrm{N}$-deuterated $\mathrm{N}$-butylacetamide. The dilution effects are shown by arrows as mentioned above. The Raman activities of the bands and the effect of substituting $\mathrm{N}^{15}$ for $\mathrm{N}^{14}$ are shown in Table II where the effects of dilution also are summarized.

Spectra were taken of $\mathrm{N}$-butylacetamide and $\mathrm{N}$ deuterated N-butylacetamide where $60 \%$ of the nitrogen was the $\mathrm{N}^{15}$ isotope. The bands of the $\mathrm{N}^{15}$ species are too close to the corresponding ones of the $\mathrm{N}^{14}$ species to be resolved, and the peaks of the samples with the enriched isotope are undoubtedly between the peaks of pure $\mathrm{N}^{16}$ and pure $\mathrm{N}^{14}$ species. The shifts indicated in this paper for $\mathrm{N}^{16}$ substitution are twice the observed shifts and this allows roughly for the fact that the isotopic species used was not pure. The results of work with $\mathrm{N}^{15}$-butylacetamide and $\mathrm{N}$-deuterated $\mathrm{N}^{15}$-butylacetamide also are shown in Table II.

\section{DISCUSSION}

All members of the homologous series of compounds discussed in this paper are formed from the previous members by addition of a $\mathrm{CH}_{2}$ group to a particular part of the molecule. This addition of three atoms will be accompanied by an increase in the number of fundamental vibrations of the molecule by $3 \times 3=9$. However, the addition of $\mathrm{CH}_{2}$ groups to a molecule cannot be expected merely to lead to new bands which can be identified with some vibrations involving only the $\mathrm{CH}_{2}$ group. Some of the bands of the parent compound will also be affected since some of the vibrations of the added $\mathrm{CH}_{2}$ group interact with some of the vibrations of the parent compound. Thus the spectra of successive members of the homologous series will differ not only in the appearance of new bands but also in some change in the frequency and intensity of the bands near the new ones.

We have first attempted to find bands for higher members of the acetamide series and the propionamide series which can be related to those of the first member. To do this we used the following four criteria of correlation:

1. Position of the band in the spectrum,

2. Intensity of the band,

3. Width of the band, and

4. Behavior of the band under dilution in nonpolar solvents.

Bands similar in these respects were considered related. Such bands are joined by broken lines in Figs. 1 and 2 .

The scheme of correlation of these bands in the acetamide series can be tested much more rigorously since for the first and last members the Raman activity and the influence of replacing the amide $H$ by $D$ are also known, and therefore the resemblances of the bands in this respect can also be investigated.

First we had to establish a correlation between the bands of $\mathrm{N}$-butylacetamide and those of $\mathrm{N}$-deuterated $\mathrm{N}$-butylacetamide. This correlation is presented in Table II where corresponding bands have been arranged in the same horizontal line. It is seen that bands on the same horizontal line generally have similar properties in regard to infrared and Raman activity, influence of dilution, and influence of $\mathrm{N}^{15}$ substituion, and therefore these properties support the correlation implied in the table.

However, several facts should be noted. The band at $1555 \mathrm{~cm}^{-1}$ disappears on deuteration; a new band appears at $1425 \mathrm{~cm}^{-1}$, and the band at $1464 \mathrm{~cm}^{-1}$ becomes more intense. Both these bands of the deuterated compound shift to lower frequencies on dilution, as did the $1555-\mathrm{cm}^{-1}$ band of the undeuterated compound. This suggests that the motions corresponding to the $1555-\mathrm{cm}^{-1}$ and the $1464-\mathrm{cm}^{-1}$ bands on deuteration mix extensively.

At $1292 \mathrm{~cm}^{-1}$ there are two superimposed bands in N-butylacetamide. On deuteration these split. Apparently the sensitivity to $\mathrm{N}^{15}$ substitution and to dilution are to be associated with the one of these bands at $988 \mathrm{~cm}^{-1}$ and the Raman activity with the other at $1299 \mathrm{~cm}^{-1}$. 


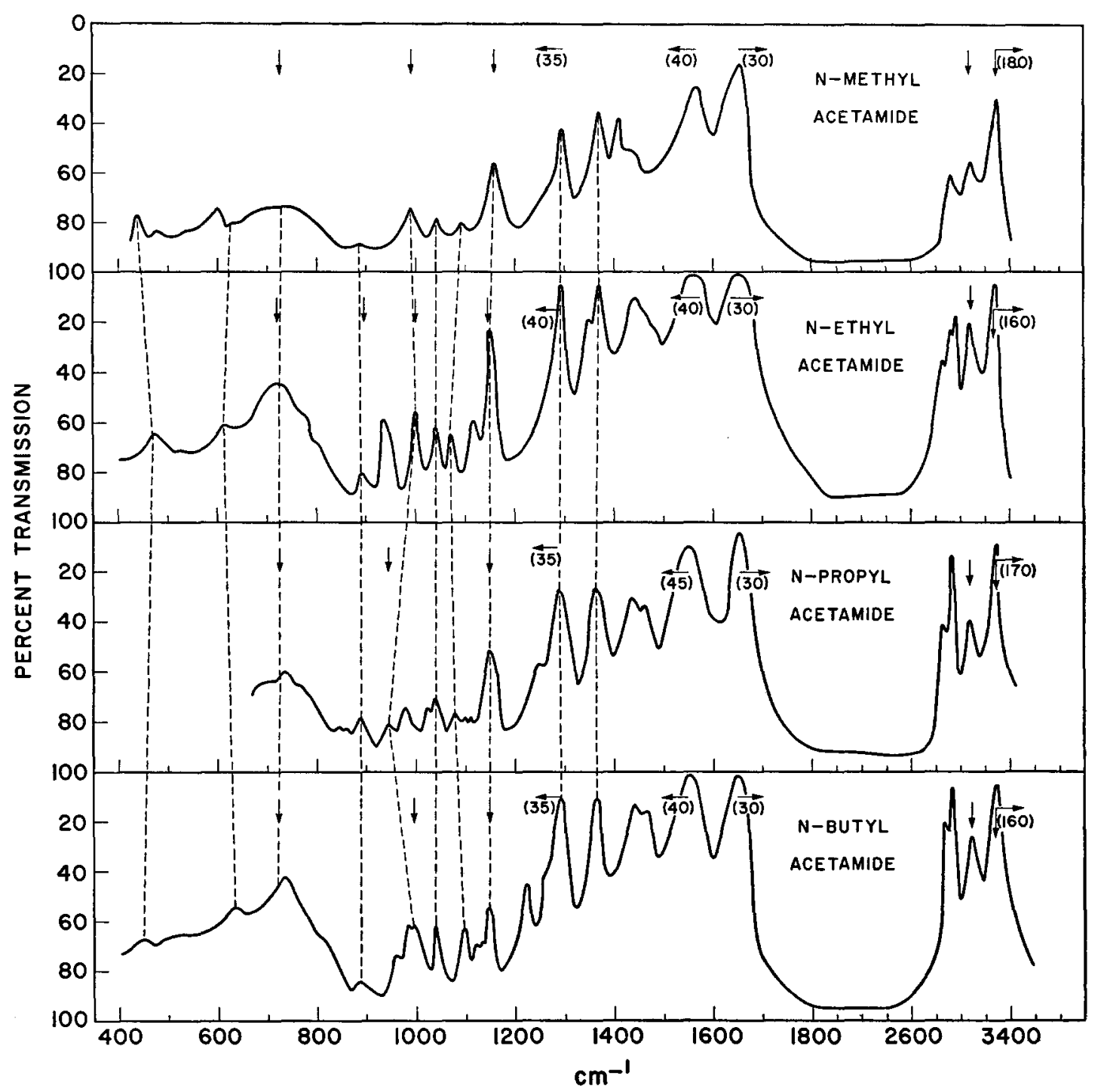

FIG. 1. Infrared spectra of four monosubstituted acetamides in the liquid state. $\downarrow$ indicates decrease in intensity on dilution in nonpolar solvents. $(n)$ indicates a shift of $n \mathrm{~cm}^{-1}$ in a band on dilution in nonpolar solvents. Broken lines connect corresponding bands.

No band in N-deuterated N-butylacetamide was related to the $1133-\mathrm{cm}^{-1}$ band of $\mathrm{N}$-butylacetamide. Such a very weak band is easily obscured and its absence in the deuterated amide does not invalidate the correlation given in Table II.

In N-butylacetamide the loss of intensity of the 984$\mathrm{cm}^{-1}$ band on $\mathrm{N}^{15}$ substitution may be because the intensity is borrowed from the nearby band at $961 \mathrm{~cm}^{-1}$ and when the latter is shifted away the extent of mixing is decreased. Thus the loss of intensity on $\mathrm{N}^{15}$ substitution need not be an inherent property of this band and the absence of a similar effect in $\mathrm{N}$-deuterated $\mathrm{N}$-butylacetamide is not a serious objection to the correlation.

No infrared spectra for $\mathrm{N}$-deuterated $\mathrm{N}$-butylacetamide were obtained below $700 \mathrm{~cm}^{-1}$, and in this region the correlations are based on band position and Raman activity alone.
Our data do not enable us to distinguish between two correlations of the bands given below:

$\begin{array}{ccccc}\begin{array}{c}\text { N-butyl- } \\ \text { acetamide }\end{array} & \begin{array}{c}\text { N-deuterated } \\ \text { N-butyl- } \\ \text { acetamide }\end{array} & \begin{array}{c}\text { N-butyl- } \\ \text { acetamide }\end{array} & \begin{array}{c}\text { N-deuterated } \\ \text { N-butyl- } \\ \text { acetamide }\end{array} \\ 1292 & 988 & \text { or } & 1292 & 1126 \\ 1148 & 1126 & & 1148 & 988\end{array}$

We have adopted the former correlation since it is most closely analogous to suggestions of earlier workers, ${ }^{1,2}$ and agrees well with the results on proteins. ${ }^{6}$

The more rigorous test of the suggested correlation of the bands for the acetamide series is now possible through a comparison of additional properties of the

${ }^{6}$ Beer, Sutherland, Tanner, and Wood, Proc. Roy. Soc. (London) (to be published). 


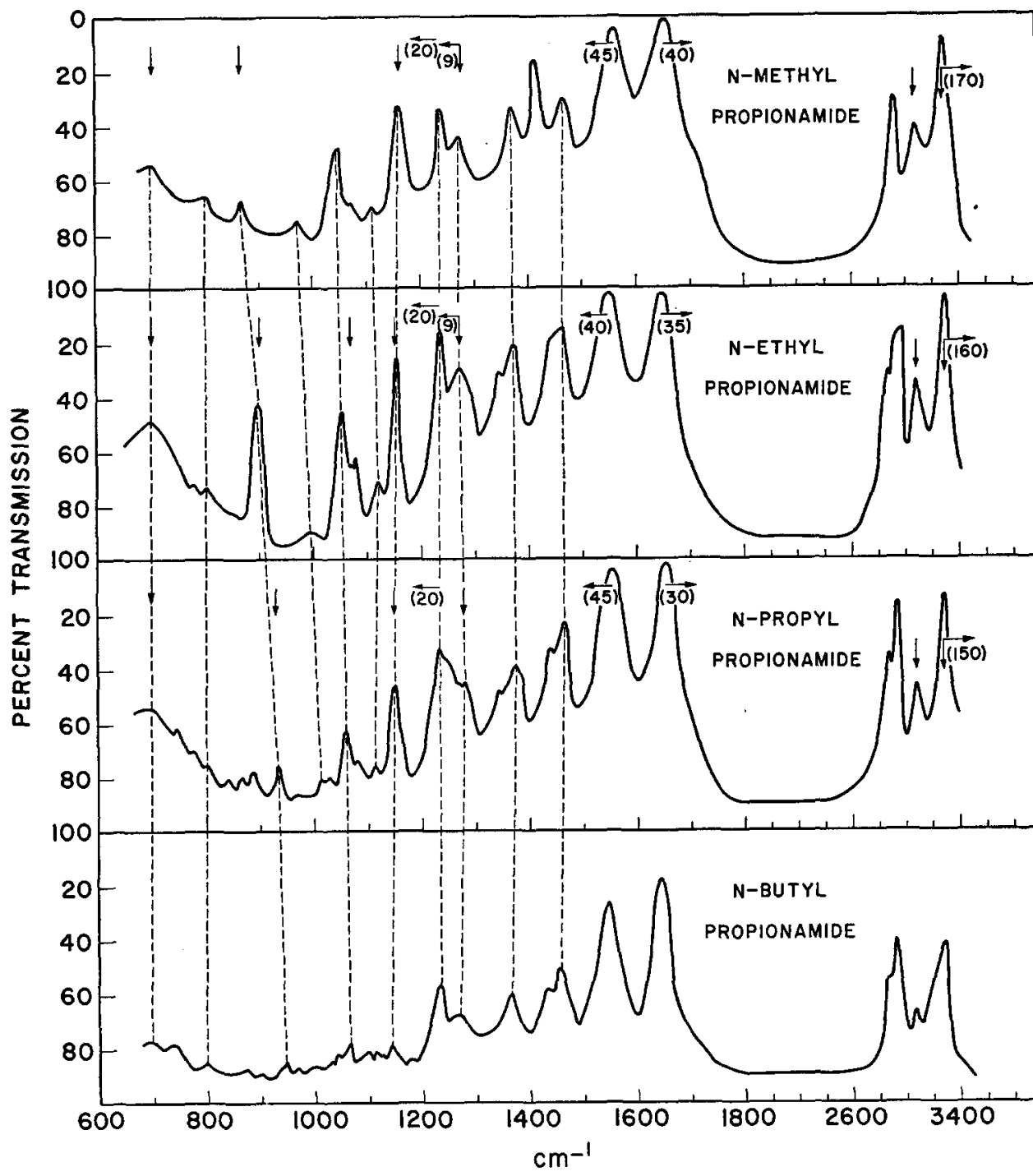

Fig. 2. Infrared spectra of four monosubstituted propionamides in the liquid state. $\downarrow$ indicates decrease in intensity on dilution in nonpolar solvents. $(n)$ indicates a shift of $n \mathrm{~cm}^{-1}$ on dilution in nonpolar solvents. Broken lines connect corresponding bands.

bands on $\mathrm{N}$-methylacetamide and $\mathrm{N}$-butylacetamide. For the former the data are those of Mizushima and co-workers. ${ }^{1,7}$ For N-butylacetamide the data are ours and are given in Fig. 1 and Table II. The data for the two substances are summarized in Table III. Bands on the same horizontal line are the ones joined by the broken lines in Fig. 1. Bands above $1700 \mathrm{~cm}^{-1}$ are not included in the table since these are now reliably attributed to $\mathrm{NH}$ and $\mathrm{CH}$ stretching vibrations and have already been thoroughly discussed previously. ${ }^{8,9}$

On comparing the bands of Table III it is seen that there are no serious discrepancies in the characteristics of those which are correlated. The solution and deuteration effects are virtually identical and so are the Raman

\footnotetext{
${ }^{7}$ Mizushima, Shimanouchi, Nagakura, Kuratari, Tsuboi, Baba, and Fujioka, J. Am. Chem. Soc. 72, 3490 (1950).

${ }^{8}$ G. B. B. M. Sutherland, Advances in Protein Chem. 7, 291 (1952).

9 L. S. Bellamy, The Infrared Spectra of Complex Molecules (Methuen and Company, Ltd., London, England, 1954).
}

activities of the correlated bands. Thus it may now be concluded that the correlations proposed on the basis of frequency, infrared intensity, band width, and solution effect are confirmed by Raman activity and by the effect of replacing the peptide $H$ by $D$. These results increase one's confidence in such correlations very considerably.

Now that corresponding bands in the series have been determined it is possible to identify those bands in the higher members which do not appear in the parent compound and therefore are largely associated with the addition of $\mathrm{CH}_{2}$ groups. It has been mentioned earlier that when a $\mathrm{CH}_{2}$ group is added to the molecule the number of vibrations is increased by nine. Adding another $\mathrm{CH}_{2}$ group will lead to another nine vibrations, and so on. Of each set of nine new vibrations, two are separable $\mathrm{CH}$ stretching modes, and one is a separable symmetrical $\mathrm{CH}$ deformation mode. These three new bands will show up in a manner now well understood and will not be discussed further. Of the remaining six 
Fig. 3. Infrared spectrum of N-deuterated N-butylacetamide in the liquid state. $\downarrow$ indicates decrease, $\uparrow$ indicates an increase in the intensity of a band on dilution in nonpolar solvents. $(n)$ indicates a shift of $n \mathrm{~cm}^{-1}$ on dilution in a nonpolar solvent.

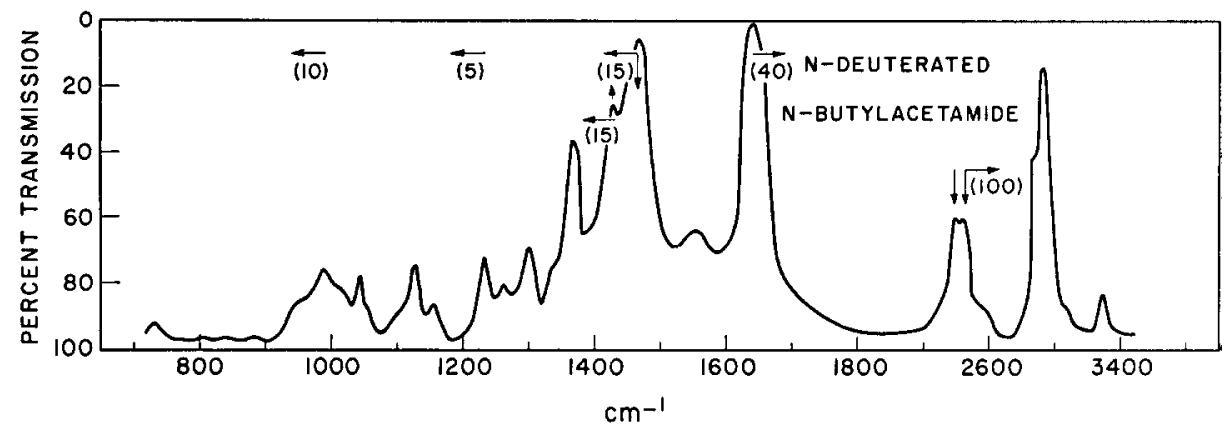

vibrations, three are associated with one wagging mode, one rocking mode, and one twisting mode, and three with additional skeletal motions of the molecule. These vibrations are not separable and therefore accurate frequencies cannot be stated for them. However, work on hydrocarbons ${ }^{10}$ has indicated the regions of the spectrum where such frequencies may be expected to lie. On the basis of that work, one is led to expect that apart from changes in the region of the $\mathrm{CH}$ stretching and symmetrical deformation vibrations, the spectrum of each member differs from that of the previous one by the appearance of one band in the region 1350-1150 $\mathrm{cm}^{-1}$ corresponding to the $\mathrm{CH}_{2}$ wag, one band in the region 1350-1150 cm $\mathrm{cm}^{-1}$ corresponding to the $\mathrm{CH}_{2}$ twist, one band in the region $1100-700 \mathrm{~cm}^{-1}$ corresponding to the $\mathrm{CH}_{2}$ rock, and 3 bands in the region below $1300 \mathrm{~cm}^{-1}$ corresponding to the skeletal motions.

In Fig. 4 the bands not present in the $\mathrm{N}$-methyl parent compounds of the two series of amides are shown for the region below $1400 \mathrm{~cm}^{-1}$. On the basis of the above discussion one would expect six bands for the N-ethyl members; $2 \times 6$ for the $\mathrm{N}$-propyl members, and so on. It would seem from Fig. 4 that the number of bands observed is less than anticipated.

The failure to detect all the predicted bands is probably due to an inability to resolve them. Accidental degeneracy in such complex molecules is often found. This becomes evident when perturbation of a molecule leads to splitting of a band, indicating two superimposed bands which respond differently to the perturbation. An example of a degeneracy thus revealed is found in N-butylacetamide at $1292 \mathrm{~cm}^{-1}$. On deuteration a part of this band moves to $988 \mathrm{~cm}^{-1}$, but another part remains. That the remaining part is not due to residual undeuterated $\mathrm{N}$-butylacetamide is shown by the fact that the band does not move on dilution. That this band is double is revealed also on dilution of $\mathrm{N}$-butylacetamide when the main part of the band moves to $1260 \mathrm{~cm}^{-1}$. Thus, despite the fact that not all of the predicted bands could be resolved, it is felt that a rational correlation of the spectra of the higher members of the series with the lower members has been attained.

An attempt will now be made to describe the vibra-

${ }^{10}$ N. Sheppard and D. M. Simpson, Quart. Revs. (London) 1, 19 (1953). tions to be associated with these bands, starting at the high frequencies:

1. The band at $3280 \mathrm{~cm}^{-1}$ is present in all monosubstituted amides and is now accepted as the $\mathrm{NH}$ stretching frequency.

2. The small band at $3060 \mathrm{~cm}^{-1}$ has been the subject of much controversy. ${ }^{8,9}$ One proposal has been that it is the first overtone of the $1550 \mathrm{~cm}^{-1}$ band and that it derives its intensity from the $\mathrm{NH}$ stretching band at $3280 \mathrm{~cm}^{-1}$. Strong support for this theory comes from the result of the $\mathrm{N}^{15}$-butylacetamide spectrum. First of all, the $3060 \mathrm{~cm}^{-1}$ band shifts to lower frequencies by about $20 \mathrm{~cm}^{-1}$, and this is about twice as much as the shift for the $1550 \mathrm{~cm}^{-1}$ band. Also, this shift away from the $3280 \mathrm{~cm}^{-1}$ band is accompanied by a loss in intensity. This is in accord with the view that the intensity is borrowed, since the mixing of the bands is complete if the bands fall at the same frequencies, and diminishes as the separation from the other band increases. A corresponding doubling of the ND stretching frequency in deuterated amides can be explained by supposing that there is resonance with the combination band $(1290+1126) \mathrm{cm}^{-1}$. A serious objection to this view has been the presence of the $3060 \mathrm{~cm}^{-1}$ band in lactams in spite of the fact that the $1550 \mathrm{~cm}^{-1}$ band is absent. Recent results, ${ }^{11}$ however, indicate that the band is present in lactams but is very weak. Thick layers of $\epsilon$-caprolactam reveal a weak band at 1560 $\mathrm{cm}^{-1}$. This band on dilution in tetrachloroethylene moves to $1540 \mathrm{~cm}^{-1}$. Also the Raman spectrum of $\alpha, \gamma$ butyrolactam shows a weak band at $1560 \mathrm{~cm}^{-1}$, while a $5 \%$ solution of $\alpha, \gamma$-butyrolactam in $\mathrm{CCl}_{4}$ shows this band shifted to $1535 \mathrm{~cm}^{-1}$.

3. The region of the spectrum around $2900 \mathrm{~cm}^{-1}$ is to be associated with the various $\mathrm{CH}$ stretching frequencies. They are now well understood ${ }^{9.10}$ and were not investigated by us in detail.

4. The band near $1650 \mathrm{~cm}^{-1}$ has been termed the Amide I band and is now accepted as largely a CO stretching vibration. ${ }^{8,9,12}$ The band is unaffected by $\mathrm{N}^{15}$ substitution and is only slightly sensitive to changes. in substitution on the nitrogen and the carbonyl carbon. In N-methylformamide, it is at $1667 \mathrm{~cm}^{-1}$ but in all the other amides we studied it is between $1656 \mathrm{~cm}^{-1}$

${ }^{11} \mathrm{M}$. Beer (unpublished results).

12 W. C. Price and R. D. B. Fraser, Nature 170, 490 (1952). 
TABLE II. Correlation of the bands of N-butylacetamide and N-deuterated N-butylacetamide.

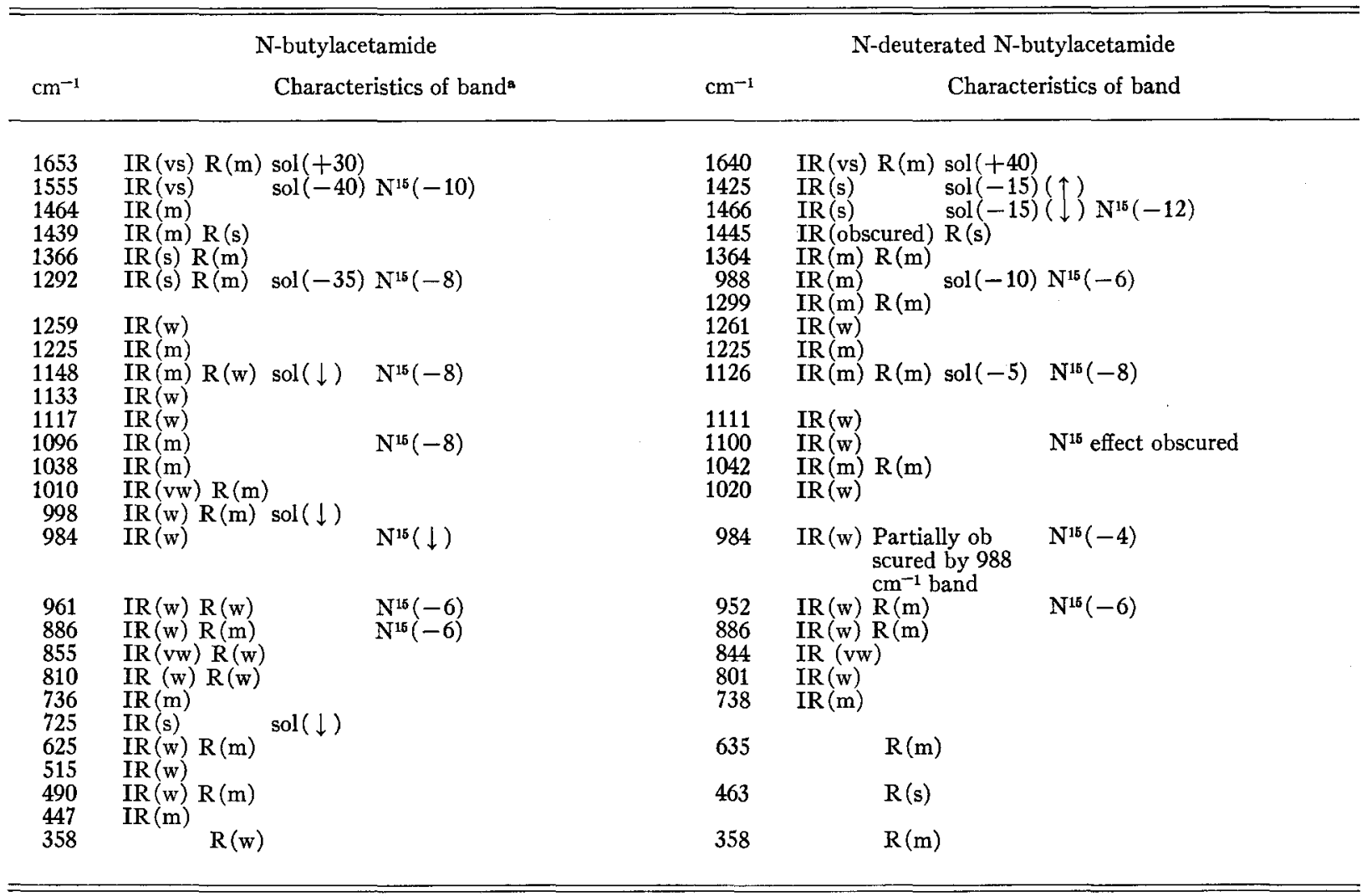

a IR and $R$ indicate infrared and Raman activities respectively. vs, s, m, w, vw indicate very strong, strong, medium, weak, and very weak respectively. sol refers to change of band on dilution, $N^{15}$ to change of the band on replacing $N^{14}$ by $N^{15}$. $(\downarrow)$ indicates a decrease and $(\uparrow)$ an increase in intensity, while a number in brackets gives the shift of the band in $\mathrm{cm}^{-1}$.

and $1650 \mathrm{~cm}^{-1}$. In deuterated $\mathrm{N}$-butylacetamide the band shifts to lower frequencies by about $20 \mathrm{~cm}^{-1}$ in the pure liquid. In solutions which are sufficiently dilute to break most of the hydrogen bonds, the position of the band in the undeuterated and deuterated compounds is virtually the same. This leads to the interesting conclusion that the added mass of the deuterium makes itself felt in the Amide I frequency primarily intermolecularly across the hydrogen bond.

5. The band near $1550 \mathrm{~cm}^{-1}$ has been termed the Amide II band and is considered a mixed vibration of $\mathrm{NH}$ deformation and $\mathrm{CN}$ stretch. ${ }^{12}$ On deuteration it moves to $1466 \mathrm{~cm}^{-1}$ in N-butylacetamide. On substituting $\mathrm{N}^{15}$ the peak of the $1466 \mathrm{~cm}^{-1}$ band shifts by 10 $\mathrm{cm}^{-1}$ to lower frequency and at the same time gives up some of its intensity to the $1440 \mathrm{~cm}^{-1}$ band. This is a very clear example of a Fermi type resonance, the other band involved almost certainly being the deformation of the $\mathrm{CH}_{2}$ on the nitrogen atom, as will be explained below.

6. The group of bands between $1300 \mathrm{~cm}^{-1}$ and 1500 $\mathrm{cm}^{-1}$ are associated with deformation vibrations of the $\mathrm{CH}$ bonds. They can now be understood.

(a) The band at $1465 \mathrm{~cm}^{-1}$ has already been identified as the $\mathrm{CH}_{2}$ deformation vibration. ${ }^{10}$ Its position is very constant and its intensity increases with the number of $\mathrm{CH}_{2}$ groups.

(b) A weak band at $1430 \mathrm{~cm}^{-1}$ to $1450 \mathrm{~cm}^{-1}$ is often obscured but can be detected in N-methylacetamide, $\mathrm{N}$-ethylacetamide, and $\mathrm{N}$-deuterated N-butylacetamide. It is attributed to the asymmetrical deformation of methyl groups attached to carbon atoms. This assignment is consistent with that given by other workers. ${ }^{9,10}$

(c) At $1440 \mathrm{~cm}^{-1}$ a fairly strong band appears in all the amides except the $\mathrm{N}$-methyl ones. This band is attributed to the deformation vibrations of the $\mathrm{CH}_{2}$ group adjacent to the nitrogen atom.

(d) At $1408 \mathrm{~cm}^{-1}$ a band appears only in compounds having methyl groups on the nitrogen atom. The band is attributed to the symmetrical deformation of the methyl group on the nitrogen atom.

(e) At $1370 \mathrm{~cm}^{-1}$ a band is always found in compounds with methyl groups. This band is the symmetrical deformation of the methyl group attached to a carbon atom, and has already been identified by other workers..$^{9,10}$

7. Somewhat below $1300 \mathrm{~cm}^{-1}$ the amide III band is always found. The band is characterized by considerable width and intensity, by a shift of about $35 \mathrm{~cm}^{-1}$ to lower frequencies on dilution, and by a great sensitivity 
HOMOLOGOUS SERIES OF MONOSUBSTITUTED AMIDES, SPECTRA 1103

TABLE III. Correlation of the bands of N-methylacetamide and N-butylacetamide.

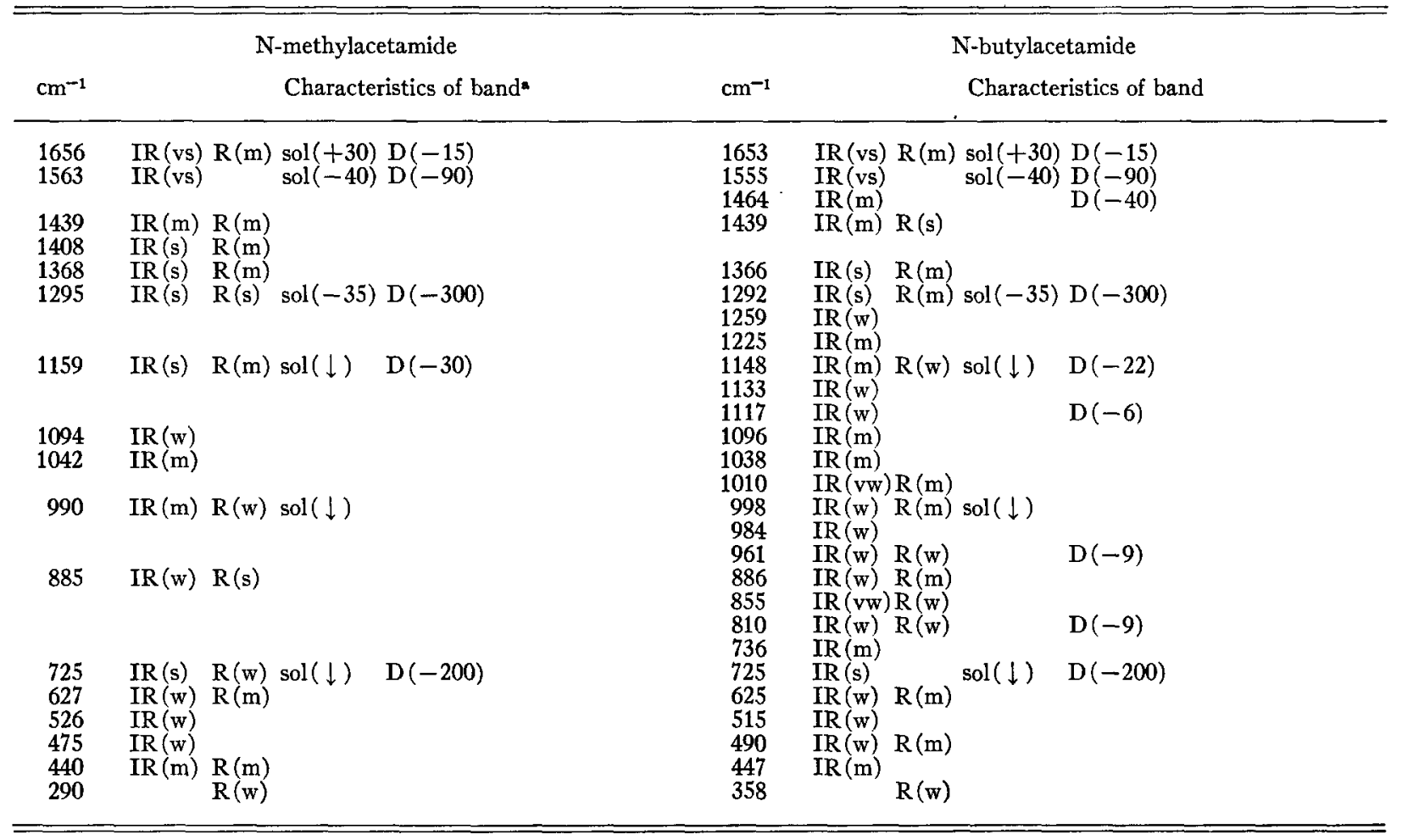

a IR and R indicate infrared and Raman activities respectively, vs, s, m, w, vw indicate very strong, strong, medium, weak, and very weak, respectively. sol refers to change of band on dilution, $\mathbf{D}$ to change of the band on replacement of the peptide hydrogen by deuterium $(\downarrow)$ indicates a decrease in intensity, while a number in brackets gives the shift of the band in $\mathrm{cm}^{-1}$.

to substitution of $\mathrm{D}$ for the peptide $\mathrm{H}$. This band has also been described before. ${ }^{12}$ In the propionamide series there are two bands between $1200 \mathrm{~cm}^{-1}$ and 1300 $\mathrm{cm}^{-1}$ which show sensitivity to dilution. In the case of $\mathrm{N}$-methylpropionamide these bands lie at $1235 \mathrm{~cm}^{-1}$ and $1260 \mathrm{~cm}^{-1}$. On dilution the sum of the shifts of these two bands is roughly the same as the shift of the single amide III band in the acetamides. Thus it must be concluded that the amide III band is"split in the propionamides.
8. Near $1160 \mathrm{~cm}^{-1}$ a band appears which in the acetamides has been attributed by Miyazawa et al. ${ }^{1}$ and by DeGraaf and Sutherland ${ }^{2}$ to a wagging motion of the $\mathrm{CH}_{3}$ on the nitrogen. This band is present at very nearly the same frequency in the propionamides as well. This suggests little sensitivity to change of substitution on the carbonyl carbon. Also on $\mathrm{N}^{15}$ substitution the band moves to a lower frequency by about $1 \%$, suggesting appreciable involvement of the nitrogen atom. The band shifts to lower frequencies when the
Fig. 4. Bands in the higher members of the homologous series which are additional to those present in the N-methyl members.

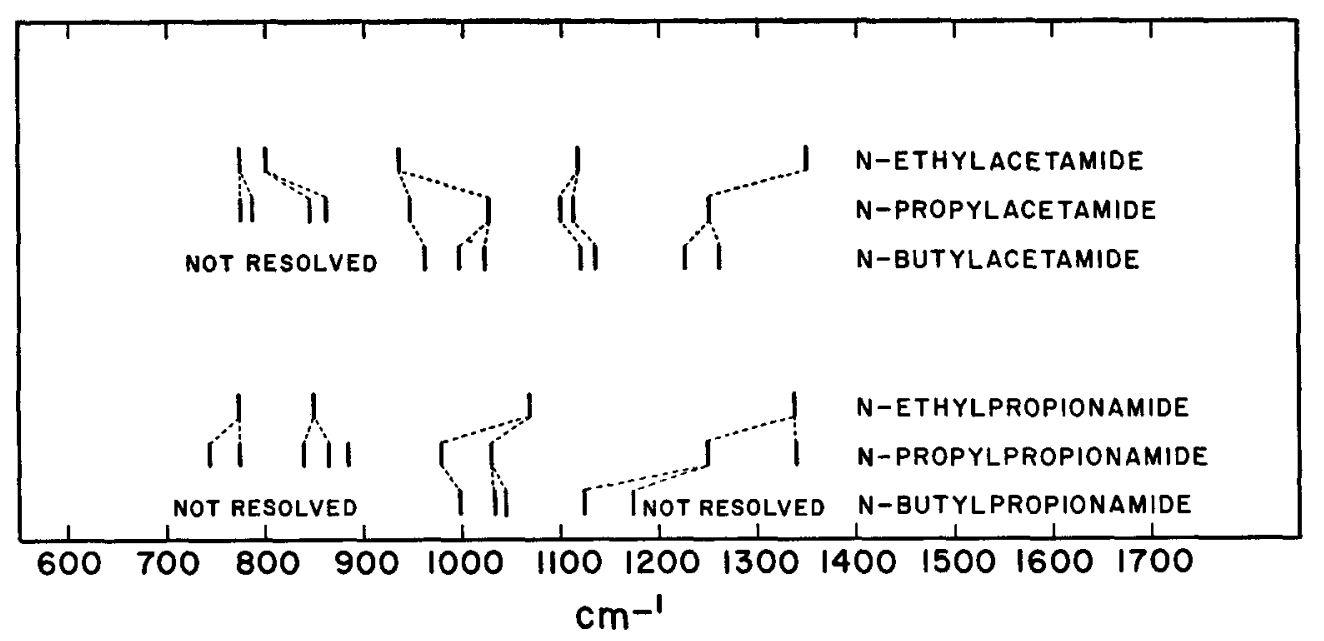


methyl on the nitrogen is replaced by ethyl, but it moves little on going to propyl and butyl. All of these facts confirm the earlier assignment of a skeletal motion involving the nitrogen atom and the carbon substituent on it.

9. The band just below $1100 \mathrm{~cm}^{-1}$ has been assigned to a skeletal motion involving $\mathrm{C}-\mathrm{CONH}-\mathrm{C}$. Our data are in agreement with this assignment and the shift on $\mathrm{N}^{15}$ substitution shows that the nitrogen atom is involved to about the same degree as in the band at $1160 \mathrm{~cm}^{-1}$. In moving stepwise to higher members of the homologous series in this region of the spectrum, too, each substance shows one more band than the previous one.

10. The band near $1040 \mathrm{~cm}^{-1}$ is unchanged in the acetamide series and not influenced by $\mathrm{N}^{15}$ substitution, in agreement with the assignment of Miyazawa et al. ${ }^{1}$ to rocking of the methyl group on the carbonyl. Even in the propionamides this band is clearly visible and has a position only slightly different from that in the acetamides. Thus the $\mathrm{CH}_{3}$ rocking is not sensitive to its environment. This region too is one of growing complexity as one goes to the higher homologs.

11. The band at $980 \mathrm{~cm}^{-1}$ lies in a region where on lengthening the chains on the nitrogen or carbonyl carbon substituents new bands appear and these become mixed with each other.

12. At $880 \mathrm{~cm}^{-1}$ a weak but constant band is observed in all the acetamides but becomes mixed with other bands in the propionamides. On substituting $\mathrm{N}^{15}$ the band moves to lower frequencies by about $\frac{1}{2} \%$.

13. The very constant band near $700 \mathrm{~cm}^{-1}$ is always present and has already been assigned to $\mathrm{NH}$ out-ofplane deformation. ${ }^{13}$

14. The band near $625 \mathrm{~cm}^{-1}$ is probably related to the one at $618 \mathrm{~cm}^{-1}$ in $\mathrm{N}$-methylformamide. Its insensitivity to changes in the substituent on the nitrogen support its assignment to a $\mathrm{CO}$ motion.

15. Bands appear near 515,490 , and $447 \mathrm{~cm}^{-1}$ in $\mathrm{N}$-methylacetamide and $\mathrm{N}$-butylacetamide, but not in $\mathrm{N}$-methylformamide. The corresponding motions are probably skeletal vibrations involving also the carbon adjacent to the carbonyl carbon.

\section{GENERAL CONCLUSIONS}

The identification of the bands in the spectra of asymmetrical molecules is difficult for two reasons. First, in the absence of symmetry properties, no simplification is possible through the subdivision of the vibrational modes into species. Secondly, no strict selection rules exist as a guide to intensities. Important

${ }^{13}$ H. B. Kessler and G. B. B. M. Sutherland, J. Chem. Phys. 21, 570 (1953). information can, however, be obtained about the nature of bands by studying a homologous series of compounds and observing the gradual spectral changes associated with introduction of particular groups. The present study on two homologous series of amides indicates that many of the bands of the higher members can be correlated with those of the parent substance on the basis of frequency, intensity, band width, and influence of dilution. The remaining bands which appear in specific regions can be systematically associated with the additional $\mathrm{CH}_{2}$ groups of the higher members of the series. Finally the behavior of the bands in the homologous series is often an important guide in the assignment of the bands to vibrations of the molecule.

The present results on amides are also significant in connection with work relating to proteins. Infrared studies of protein structure using polarised light generally depend on the assumption that the transition moment vector associated with vibrations is fixed relative to the peptide link. ${ }^{6}$ Only when this is true can variations in dichroic ratio have reliable structural implications. Bands which are sensitive to the environment of the peptide link are poor choices for such dichroic studies. On the basis of the present study it is possible to make strong recommendations for suitable bands. The most constant bands are the NH stretching frequency near $3300 \mathrm{~cm}^{-1}$, the amide I near $1650 \mathrm{~cm}^{-1}$, the amide II near $1550 \mathrm{~cm}^{-1}$, and the NH out-of-plane deformation near $700 \mathrm{~cm}^{-1}$. A band which is almost certainly not a sound choice is the amide III band near $1300 \mathrm{~cm}^{-1}$ which appears to split in the propionamides, showing strong mixing with motions of the substituents on the carbonyl carbon. Another band which is very sensitive to small perturbations is the amide II band in deuterated compounds. This is clearly shown in the marked effect on substituting $\mathrm{N}^{15}$.

It may be hoped that in synthetic polypeptides the detailed investigation of the positions of those peptide bands which are sensitive to the environment of the peptide group will lead to structural or chemical information on the proteins. Such an approach however will have to await more detailed studies of homologous series of peptides.

\section{ACKNOWLEDGMENTS}

The authors gratefully acknowledge financial assistance from the United States Public Health Service and the Rockefeller Foundation. One of us (H. B. K.) also acknowledges a research fellowship from the Dow Chemical Company, Midland, Michigan. The hospitality of Dr. R. C. Taylor in his Raman Spectroscopy Laboratory and the helpful criticisms of Dr. R. N. Jones were much appreciated. 